\title{
Intermediaries and corruption
}

\author{
Kevin Hasker, Cagla Okten* \\ Department of Economics, Bilkent University, 06800 Bilkent, Ankara, Turkey
}

Received 8 April 2005; accepted 16 June 2006

Available online 12 March 2007

\begin{abstract}
Surveys of businessmen and anecdotal evidence blame intermediary agents (middlemen hired by corporations and individuals) for increasing corruption in the developing world. Although this problem has gained the attention of policy makers, there has been little formal analysis of it in the economics literature. In a game theoretic model analyzing the interaction between clients, public official and intermediary agents, we find that intermediary agents worsen the impact of corruption and that traditional methods of fighting corruption can actually increase corruption in the presence of intermediary agents.
\end{abstract}

() 2007 Elsevier B.V. All rights reserved.

JEL classification: D73; K42; L14; O17

Keywords: Corruption; Bureaucracy; Intermediary agent

\section{Introduction}

Despite the widespread introduction of laws against bribery for international businesses, financial corruption remains a serious problem. In a survey of business development directors of 50 US and 50 European companies, an overwhelming majority of those surveyed stated that US companies used middlemen such as agents, joint venture partners or foreign subsidiaries to avoid direct involvement with corruption either 'regularly' or 'occasionally' (Control Risks Group, Information Services Team, 1998). There is also anecdotal evidence that blames intermediary agents (middlemen hired by corporations and individuals) for increasing corruption in the developing world (Wiehen, 1999). Although this problem has gained the attention of policy makers and non-governmental organizations, there has been little formal analysis of it in the economics literature.

What are the effects of intermediary agents on corruption? Do the solutions to the corruption problem change in the presence of intermediaries? In this paper, we develop a simple model that captures the effect of key policy variables that are used to fight corruption. We then examine how the presence of intermediary agents change the amount of corruption and the effectiveness of policy variables in fighting corruption. We show that intermediaries worsen the impact of corruption and make it impossible to eradicate corruption using traditional techniques. In fact standard techniques such as increasing monitoring or penalties can worsen the impact of corruption. Methods that do not consider the impact of intermediaries are unlikely to succeed.

\footnotetext{
* Corresponding author. Tel.: +90 312290 2225; fax: +90 3122665140.

E-mail address: cokten@bilkent.edu.tr (C. Okten).
} 
Several authors have pointed out that intermediary agents may enable corruption by acting as guarantors in the dealing between client and bureaucrat (Bayar, 2005; Lambsdorff, 2002b; Oldenburg, 1987; della Porta and Vanucci, 1999). There are important transaction costs, including the costs of searching for partners, determining contract conditions and enforcing contract terms, in any corrupt business deal. Intermediary agents can lower transaction costs of a corrupt deal by providing information to potential clients with respect to the capability of the bureaucrat actually to provide the required service (Lambsdorff, 2002b). When there is the possibility that the bribed officials may not deliver the promised services due to either inability or unwillingness, an established intermediary agent with superior knowledge about the trustworthiness and ability of the bureaucrat to complete the corrupt transaction can be essential. Unlike the actual supplier of a corrupt service, an intermediary may be in a position to disclose publicly her past record and establish a reputation for getting deals done. Her repeated relationship with the bureaucrat can induce cooperation from the bureaucrat to complete the corrupt transaction. We incorporate these ideas in our model by allowing that a bribed official may not always deliver the "goods" when interacting with a client directly, but always keeps his promise if an intermediary is involved.

To our knowledge, ours is one of the first papers that analyze the effects of intermediary agents on corruption in a formal model. Bayar presents a preliminary model where the analysis depends on the truthful revelation of information, even though the revelation hurts the revealers. This revelation results in bureaucrats' bribes being the bureaucrats' reservation values when intermediaries are used. One wonders why bureaucrats accept bribes from intermediaries when they do better by demanding all bribes directly. Furthermore, when intermediaries are present, all clients bribe the bureaucrats. This result contradicts casual empiricism. We often observe that some clients prefer to go through regulation rather than paying a bribe. In our model, we do not rely on truthful revelation, and, in equilibrium, there are always some clients that choose to face the regulation.

A related literature analyses a different link in the chain of agents between the public interest and individuals. Bowles and Garoupa (1997); Garoupa and Klerman (2004) and Polinsky and Shavell (2001) analyze "gatekeepers" like policemen and law enforcers whose primary job is to catch criminals. In general, these studies find that corruption of gatekeepers reduces their incentives to enforce regulations and thereby changes the optimal enforcement strategy.

In this paper we analyze "facilitators" who assist clients (those being regulated by the bureaucracy) and help them avoid regulations. In our framework every client has to meet certain regulations, and the bureaucrat may reduce regulations in exchange for bribes. Intermediary agents play a facilitating role in this exchange. One could think of gatekeepers from the law enforcement literature as an additional player who is responsible to detect any criminal activity in our bureaucrat-intermediary-client framework. Although we do not formally model the relationship between gatekeepers and potential criminals in our model, we do analyze how the effectiveness of techniques utilized by law enforcers may change.

Our focus here is on reducing corruption. We assume that there is some optimal level of regulation set by the government and that clients (individuals or firms) may be willing to pay bribes to circumvent this regulation. We show that intermediaries decrease the quantity of regulation, as expected, but do not actually change the number of bribes paid to bureaucrats. Interestingly a wide variety of techniques used by governments might worsen corruption in the presence of intermediaries. Not only increasing penalties and monitoring, but also steps such as rotating bureaucrats in order to prevent entrenchment or requiring signatures from multiple bureaucrats in order to limit their discretionary power may result in reduced regulation.

There is some empirical evidence that investors' confidence is not only adversely affected by corruption but also by the lack of predictability and confidence that accompanies corrupt deals (Campos et al., 1999; Kaufmann and Wei, 2000). Based on this evidence one could argue that intermediary agents might increase investors' confidence by increasing the predictability and reliability of corrupt deals. Lambsdorff (2002a) provides evidence to the contrary and in a cross-country study shows that confidence in corrupt deals enhances the further spread of corruption.

In the next section, we present our formal model. Section 3 presents the equilibrium without intermediaries. Section 4 presents the equilibrium in the presence of intermediary agents. In Section 5, we discuss whether solutions to the corruption problem change when intermediaries are present. Section 6 concludes.

\section{Model}

In this paper, the term corruption refers to the use of public office for private gains, where a bureaucrat entrusted with carrying out a task by the public engages in some sort of malfeasance for private enrichment that is difficult to 
monitor by the public. Specifically a corrupt bureaucrat can reduce the efficient level of regulation in exchange for a bribe.

In any model of this sort one will have three primary types of players. First is the client, the individual or the corporation that is subject to a bureaucratic regulation; second must be the bureaucrat who is responsible for administering the regulation and making sure that each client complies with it. Third is the intermediary, an entity that the client can hire to deal with the bureaucrat on his behalf. The bureaucrat will have monopoly power since clients must satisfy the regulations. There will be a large number of clients, technically a continuum. Since the market for intermediaries is informal, generally without government license or even recognition, and without high fixed costs, we assume that this market is competitive. In Section 4.2 we discuss the impact of altering this assumption.

Before the interaction the bureaucrat sets two bribe levels, the amount they demand from a client who comes directly and the amount they demand from intermediaries. One can think of this as clients and intermediaries knowing these amounts based on past interactions, but formally this is the first stage in our extensive form game. Then the intermediary determines his fees, and the client's type is determined. Next, the client chooses whether or not to use the intermediary and finally either the intermediary (if used) or the client (if intermediary is not used) decides whether or not to bribe the bureaucrat.

Clients will have a marginal opportunity cost of the regulations $\theta \in[\underline{\theta}, \bar{\theta}]$ where $0 \leq \underline{\theta}<\bar{\theta}$ with a cumulative distribution function $G(\cdot)$ (which is differentiable and has an increasing hazard rate ${ }^{1}$ ). We can interpret this difference in opportunity costs of regulations as if regulations are more difficult to meet for less worthy clients. For simplicity we normalize the mass of clients to one. A client who has to go through a level of regulation $r$ and pay fees of $t_{c}$ then has a utility:

$$
U\left(\theta, r, t_{c}\right)=v-\theta r-t_{c}
$$

where $v$ is value of service, $r \in\left\{r_{l}, r^{*}\right\}$. The level $r^{*}$ is the optimal regulation the government wants the client to face, and $r_{l}$ is the level the bureaucrat can decrease it to if he wishes; let $\Delta=r^{*}-r_{l}>0$. We assume that $v>$ $\bar{\theta} r^{*}$ or that it is always worthwhile getting the service. In the case of indifference clients will offer bribes and use intermediaries.

The intermediary's payoff then is

$$
u_{I}= \begin{cases}t_{I}-c & \text { if services are used } \\ t_{I} & \text { else. }\end{cases}
$$

where $t_{I}$ is the amount of transfers paid and received and $c$ is the opportunity cost for the client of using the intermediary. Notice that this means that $c<0$ is allowed. In a more structural model we would model the reservation price charged by the intermediary $\omega>0$ and the change in costs of the intermediary to the client would be $\Delta c / \Delta I \lesseqgtr 0$ since using the intermediary may save or cost the client his time. In general we should expect that the intermediary's knowledge and expertise should benefit the client, or $\Delta c / \Delta I<0$. Then our variable $c$ is equal to $\omega+\Delta c / \Delta I$, which may be negative. This simplification comes without loss of generality in our model since clients do not have market power. We discuss this further in Section 4.1.1.

Since in this paper we are discussing the impact of intermediaries, it does not make sense to consider the situation where intermediaries are not viable. To avoid this situation we assume that $c<\bar{\theta} \Delta$. What this assumption means is that it is not cost prohibitive for the highest type to use the intermediary in return for a lower level of regulation. Also notice how weak of an assumption this is; if we think of $\Delta$ as a period of time it will take to satisfy the regulations, then this is equivalent to assuming that the highest wage individual can always find someone who will work for less.

The bureaucrat has a simple profit function, just $\Pi=t_{b}$, where $t_{b}$ is the amount the bureaucrat is paid for being bribed. We should note that some bureaucrats might be honest and never accept bribes, and also that this bureaucrat is paid a salary that we normalize to zero.

Both bureaucrats and clients have reasons to prefer intermediaries as stated in the following two assumptions.

\footnotetext{
${ }^{1}$ It is standard to assume that the hazard rate (defined as $g(\theta) / 1-G(\theta)$ ) is increasing. This property is satisfied by normal, uniform and most other common distributions.
} 
Assumption 1. Bureaucrats bribed by

1. Clients do not always "stay bribed," i.e., sometimes they do not reduce the level of regulations.

2. Intermediaries always "stay bribed" and are never caught.

These assumptions are based on the repeated nature of the interaction between an intermediary and a bureaucrat. A client generally wants a service only once; thus after being bribed it might be easier for the bureaucrat just to take the money without reducing the amount of regulation. In other words, a bureaucrat faces a moral hazard problem since his relationship with the client is a one shot interaction. On the other hand an intermediary will have a repeated relationship with the bureaucrat, requiring the service multiple times on behalf of different clients; thus it would not be sensible for the bureaucrat to renege on the deal. As Lambsdorff (2002b) argues, the intermediary may act as the guarantor of the deal. Technically the first assumption means that clients who bribe bureaucrats directly face regulation level $r_{l}$ with probability $\eta \in(0,1)$, with probability $1-\eta$ that they face regulation level $r^{*}$. If a client uses an intermediary to pay a bribe, then the regulation level is $r_{l}$.

Governments often rotate public officials around the bureaucracy to fight corruption. Bardhan (1997) suggests periodic job rotation as an anti-corruption measure. The idea behind this policy is that a bureaucrat who does not stay in the same department for a long time will not be able to develop a reputation for taking bribes, thus it is not worth it to him to reduce the regulation level. Intermediaries, on the other hand, are private agents and can choose to remain in the same location and reap the benefits of developing a reputation for delivering corrupt services. This observation further motivates our assumption that regulation is reduced with probability $\eta<1$ when client bribes the bureaucrat directly and with probability one when he uses an intermediary.

Another interpretation for $\eta$ being less than one is the uncertainty that a client faces on the correct bureaucrat to bribe. When dealing with regulations clients generally have to interact with a large number of bureaucrats, and just because someone asks for a bribe does not mean that he can actually reduce the level of regulation. While for simplicity we represent all of these bureaucrats as a single monopolistic bureaucrat, in many regulatory settings it is undeniable that $\eta$ is less than one, and significantly so. Of course this is one advantage of using an intermediary since she would know exactly who must be bribed to reduce regulations.

The assumption that bureaucrats bribed by an intermediary cannot be caught is based on the government needing the briber's testimony to convict a bureaucrat. As Lambsdorff (2002b) argues bureaucrats prefer dealing with intermediaries to avoid the risk of exposure from corrupt deals. Formally we assume that the government investigates each bureaucrat-client interaction with probability $\rho$, and if it finds that regulation level is reduced to $r_{l}$ and that a bribe has been paid, it fines the bureaucrat by the amount $F .^{2}$ The government discovers only that regulation level is reduced without finding evidence that a bribe has been paid is not sufficient to find a bureaucrat guilty of corruption; such an outcome might be the result of an honest mistake. Hence, the government requires evidence on bribery and corruption that only the client or intermediary can provide. It is fairly simple to design an incentive scheme for truthful testimony from the client. We will assume that according to this incentive scheme, the cost of his regulation will not change as a reward for truthful testimony. On the other hand it is unlikely that the intermediary will testify against her partner in crime. Due to the repeated nature of her business with the bureaucrat, an intermediary agent is a lot more vested in the continuance of this relationship than the client. An intermediary agent who blows the whistle on the bureaucrat essentially loses her job. Thus, intermediaries never testify, and bureaucrats who are bribed by intermediaries have nothing to fear from the government. Also clients who use intermediaries will never testify since as far as they are concerned they pay a fee to the intermediary and not a bribe to the bureaucrat. Hence, our second assumption indicates that for a bureaucrat to be caught, he must have reduced the level of regulations and have been bribed directly by a client.

Notice that this model could easily be modified so that the client only sometimes confesses when he bribes the bureaucrat directly. We could also allow for the possibility that intermediaries sometimes confess; however since they generally exist in an informal sector they have little incentive for this.

The bureaucrat will choose two bribe levels, one for clients who use the intermediary $\left(b_{i}\right)$ and one for people who come directly $\left(b_{d}\right),\left\{b_{d}, b_{i}\right\} \in\{[0, \bar{\theta} \Delta] \cup \emptyset\} \times\{[0, \bar{\theta} \Delta] \cup \emptyset\}$. If a bribe is $\emptyset$ then no bribe is asked. If the client pays no bribe the regulation level is $r^{*}$.

\footnotetext{
${ }^{2} F$ might also be either jail time or lost wages.
} 
Monitoring bureaucracy $\rho$, fines on corrupt officials $F$, bureaucrat's trustworthiness $\eta$, and his discretionary power $\Delta$ are the policy variables that we will focus on in our analysis. To fight corruption, governments may investigate more cases (increase $\rho$ ), increase the penalties for bureaucrats who are caught (raise $F$ ), limit bureaucrats' discretionary power (decrease $\Delta$ ) by, for example, requiring signatures from multiple officials, and reduce bureaucrats' trustworthiness (decrease $\eta$ ) by preventing entrenchment through periodic job rotation. We are interested in analyzing the effects of these policy variables on the quantity of regulation and corruption with or without the presence of intermediary agents.

\section{The equilibrium without intermediaries}

We now present our base case, which is the equilibrium without any intermediaries. The profit function of the bureaucrat in this case is

$$
\Pi\left(b_{d}, \theta_{d}\right)= \begin{cases}\left(b_{d}-\eta \rho F\right)\left(1-G\left(\theta_{d}\right)\right) & b_{d} \neq \emptyset \\ 0 & b_{d}=\emptyset,\end{cases}
$$

where $\theta_{d}$ is the marginal type who is indifferent between paying and not paying the bribe. To explain this profit function, if $\theta \geq \theta_{d}$ then the bureaucrat's revenue is $b_{d}$. If he does not reduce the regulation he has no expected cost, and he only reduces the regulation with probability $\eta$. If he does, then with probability $\rho$ he has to pay the fine of $F$, so his expected cost per bribe accepted is $\eta \rho F$. To find the marginal type who will pay the bribe, we look at the following equation:

$$
E_{r}\left[U\left(\theta_{d}, r, b_{d}\right)\right]=U\left(\theta_{d}, r^{*}, 0\right),
$$

where $E_{r}\left[U\left(\theta_{d}, r, b\right)\right]=v-\theta_{d}\left(\eta r_{l}+(1-\eta) r^{*}\right)-b_{d}$; the solution to this is $b_{d}=\eta \theta_{d} \Delta$.

Define:

$$
H(\theta)=\theta-\frac{1-G(\theta)}{g(\theta)}
$$

then we can write the optimal level for $\theta_{d}$ as

$$
H\left(\theta_{d}\right)=\frac{\rho F}{\Delta} .
$$

If $H(\bar{\theta})<\rho F / \Delta$ then we can set $\theta_{d}=\bar{\theta}$; if $H(\underline{\theta})>\rho F / \Delta$ then we can set $\theta_{d}=\underline{\theta}$.

When bribes are offered and accepted, bureaucrat's profit is given by

$$
\Pi^{d}=\eta \Delta \frac{\left(1-G\left(\theta_{d}\right)\right)^{2}}{g\left(\theta_{d}\right)} .
$$

Notice we use a $d$ superscript in this case to facilitate comparison with the cases when the bureaucrat can accept bribes from intermediaries.

Lemma 1 (Existence). When $b_{d} \neq \emptyset$ it must be that the benefit to the highest type is higher than the expected cost to the bureaucrat.

All proofs are in Appendix which is available on the Journal of Economic Behavior website.

Notice how this model captures standard government strategies to fight corruption (Bardhan, 1997; Rose-Ackerman, 1994). To fight corruption, governments will investigate more cases (increase $\rho$ ), increase the penalties for bureaucrats who are caught (raise $F$ ), and limit bureaucrats' discretionary power by decreasing the amount he can reduce the level of regulation $(\Delta)$. In our model, these all directly decrease the amount of bribery $\left(Q_{b}^{d}=1-G\left(\theta_{d}\right)\right)$ by increasing $\theta_{d}$. Reducing $\eta$, on the other hand, directly increases the quantity of regulation $\left(Q_{r}^{d}=r^{*}-\eta \Delta\left(1-G\left(\theta_{d}\right)\right)\right)$ even though it does not directly effect $\theta_{d}$. While initially it might seem surprising that it does not change $\theta_{d}$ the intuition for this is straightforward. While reducing $\eta$ will reduce expected benefits to the client from a possible regulation reduction, it also decreases his costs proportionally since bureaucrats must lower their bribe levels for a less certain favor.

We would like to mention that in our model it does not actually matter if the fine is applied to the bureaucrat or the client. If a fine of $F_{c}$ were applied to the client who bribes with probability $\rho_{c}$ then the solution to Eq. (3) would be $b_{d}=\eta \theta_{d} \Delta-\eta \rho_{c} F_{c}$ and Eq. (5) would be $H\left(\theta_{d}\right)=\left(\rho F+\rho_{c} F_{c}\right) / \Delta$. Part of $F_{c}$ could be additional regulation the 
client might face. The implication is that the first order applying the fine to the client or the bureaucrat is unimportant; however there can be important second-order reasons for fining the client. The most basic one is that clients and bureaucrats both have finite budgets, and fining the client might be the only way to increase the total fine. Another reason is that it might be politically easier to fine clients, or court costs might be lower if two small fines are applied as opposed to one large one.

\section{The equilibrium with intermediaries}

To find the equilibrium we just need to look for the profit maximizing alternative among the four options available to the bureaucrat: (1) he never accept bribes, (2) he only accepts bribes directly from clients, (3) he only accepts bribes from intermediaries, and (4) he always accepts bribes (both directly and from intermediaries). We will find the equilibrium by first finding the bureaucrat's profits under each option and then maximizing his profits over his various options.

\subsection{Bureaucrat's profit under his four options}

The first option, never accepting bribes, will occur only when all other alternatives give a negative profit, in this case $b_{i}=\emptyset$ and $b_{d}=\emptyset$. The second option, only accepting bribes directly from clients, is essentially the same as the case without intermediaries; discussed in Section 3; now denote this as $b_{i}=\emptyset$ and $b_{d} \neq \emptyset$. This leaves the last two options to be analyzed. The third option can be characterized as $b_{i} \neq \emptyset$ and $b_{d}=\emptyset$ and the fourth as $b_{d} \neq \emptyset$ and $b_{i} \neq \theta$. Notice that throughout this analysis we only allow for intermediaries, whether or not she is used will be endogenous to the model. One general result is in the following way.

Lemma 2. If intermediaries are used and $p_{i}$ is the intermediary's fee to reduce regulation, then $p_{i}=b_{i}+c$.

This is a simple implication of the competitive nature of the intermediaries market. In Sections 4.2 .1 and 5 we discuss the impact of allowing the intermediaries to have market power on our results. In general it will not change the existence conditions though clearly it would change which types use intermediaries and reduce the bureaucrat's profit.

\subsubsection{The third option: all bribers choose to use intermediaries $\left(b_{d}=\emptyset\right)$}

This case is very similar to the case without intermediaries. The bureaucrat's profit function is

$$
\Pi\left(b_{i}, \theta_{i}\right)= \begin{cases}b_{i}\left(1-G\left(\theta_{i}\right)\right) & b_{i} \neq \emptyset \\ 0 & b_{i}=\emptyset,\end{cases}
$$

where $\theta_{i}$ is the marginal type who is indifferent between using the intermediary and not paying a bribe. Notice that here there is no expected cost since the bureaucrat will never be caught. How we determine $\theta_{i}$ depends on whether $c$ is positive or negative. If $c$ is positive clients have essentially the same choice as in the direct case, only this time he will just hire the intermediary instead of paying a bribe and his expected level of regulation will be lower, or $U\left(\theta_{i}, r_{l}, p_{i}\right)=U\left(\theta_{i}, r^{*}, 0\right)$, and then $b_{i}=\theta_{i} \Delta-c$. If $c$ is negative it is cost saving for everyone to use the intermediary; thus we will assume that everyone uses intermediaries. In this case $\theta_{i}$ is determined by $U\left(\theta_{i}, r_{l}, p_{i}\right)=U\left(\theta_{i}, r^{*}, c\right)$, or $b_{i}=\theta_{i} \Delta$. We can summarize both cases by saying that $\theta_{i}$ is found as $H\left(\theta_{i}\right)=\max \{c / \Delta, 0\}$. If $H(\underline{\theta})>\max \{c / \Delta, 0\}$ then we set $\theta_{i}=\underline{\theta}$. We use an $i$ superscript on the profit function to denote the case where all bribers choose to use intermediaries, and throughout this analysis $\theta_{i}$ denotes a person who has a choice between not bribing and using an intermediary to bribe.

When all bribers choose intermediaries, bureaucrat's profit is given by

$$
\Pi^{i}=\Delta \frac{\left(1-G\left(\theta_{i}\right)\right)^{2}}{g\left(\theta_{i}\right)}
$$

Lemma 3 (Existence). If all bribers choose to use intermediaries, then the benefit to the highest type must be greater than the cost of using the intermediary. 
Note that we always assume the condition in this lemma, which is $\bar{\theta} \Delta>c$. This assumption is equivalent to intermediaries being economically viable. Essentially this shows that if someone will use the intermediary, then this market will exist. One interpretation of $\theta$ is the opportunity cost of the clients' time. Clearly intermediaries will have a lower value for their time than $\bar{\theta}$, the highest wage in the economy, thus the only reasonable way this can fail is if the amount of regulation reduction $(\Delta)$ is trivially small. Also notice that if $c \leq 0$ then this market always exists. One must increase $c$ to stop this equilibrium.

At this point we can clarify why we allow $c \leq 0$, instead of a more formal model where the intermediary has a positive opportunity cost. If the intermediary's reservation price is $\omega>0$ and we let $\Delta c / \Delta I \leq 0$ be the change in costs to the client from using the intermediary, then the bribe fee would be $b_{i}=\theta_{i} \Delta-(\omega+\Delta c / \Delta I)$ and $H\left(\theta_{i}\right)=$ $\max \{(\omega+(\Delta c / \Delta I)) \Delta, 0\}$. Thus, the equilibrium is only affected by $c=\omega+\Delta c / \Delta I$.

\subsubsection{The fourth option: some bribers choose to use intermediaries $\left(b_{d} \neq \emptyset\right.$ and $\left.b_{i} \neq \theta\right)$}

In this case, we define $\theta_{d}^{b}$ as the lowest type who prefers bribing the bureaucrat directly to all other options. Similarly, we define $\theta_{i}^{b}$ as the lowest type who prefers using the intermediary for bribing to both bribing the bureaucrat directly and not offering a bribe. (The $b$ superscript indicates both types of bribes are accepted.) Notice that intermediaries offer a superior product because the regulation is always reduced. The value of this is increasing in $\theta$, so if type $\theta_{i}^{b}$ prefers using intermediaries to bribing directly so will everyone with $\theta \geq \theta_{i}^{b}$. This insight is critical for the following lemma.

Lemma 4. If $\theta_{d}^{b} \geq \theta_{i}^{b}$ then no one will bribe the bureaucrat directly, and $b_{d}=\emptyset$ is optimal.

Given this lemma for both direct and indirect bribes to exist it must be that $\theta_{d}^{b}<\theta_{i}^{b}$ and therefore $b_{d}<b_{i}$. The profit function of the bureaucrat is

$$
\Pi\left(b_{d}, b_{i}\right)=\left(b_{d}-\eta \rho F\right)\left(G\left(\theta_{i}^{b}\right)-G\left(\theta_{d}^{b}\right)\right)+b_{i}\left(1-G\left(\theta_{i}^{b}\right)\right)
$$

and $\theta_{d}^{b}$ is determined as before, or $b_{d}=\theta_{d}^{b} \eta \Delta$. The marginal type who uses the intermediary now is indifferent between using the intermediary and bribing directly, or

$$
U\left(\theta_{i}^{b}, r_{l} p_{i}\right)=E_{r}\left[U\left(\theta_{i}^{b}, r, b_{d}\right)\right],
$$

and this gives us $b_{i}=b_{d}+(1-\eta) \theta_{i}^{b} \Delta-c$. Using this we can simplify the profit function to

$$
\Pi\left(\theta_{d}^{b}, \theta_{i}^{b}\right)=\left(\eta \Delta \theta_{d}^{b}-\eta \rho F\right)\left(1-G\left(\theta_{d}^{b}\right)\right)+\left((1-\eta) \theta_{i}^{b} \Delta+\eta \rho F-c\right)\left(1-G\left(\theta_{i}^{b}\right)\right) .
$$

The most startling thing about this objective function is that $\theta_{d}^{b}=\theta_{d}$. In other words, the lowest type who prefers bribing the bureaucrat directly to all other options is unchanged from the case where there is no intermediary, or it is the $\theta_{d}$ that solves $H\left(\theta_{d}\right)=\rho F / \Delta$ (with $\theta_{d}=\underline{\theta}$ if $H(\underline{\theta})>\rho F / \Delta$ ). This result, however, would be true in general. It is based on the fact that this marginal person is still making the same decision as before. He is still choosing between not bribing and facing the regulation or paying the bribe. Hence, from now on we will drop the $b$ superscript for this type and use $\theta_{d}$.

Of course this logic does not hold for the person indifferent between using an intermediary and any other method; it is now

$$
H\left(\theta_{i}^{b}\right)=\frac{c-\eta \rho F}{(1-\eta) \Delta}
$$

We do not have any caveat on what to do when there is no such $\theta$; and if $H(\underline{\theta})>(c-\eta \rho F) /(1-\eta) \Delta$ then there is no one paying a direct bribe, if $H(\bar{\theta})<(c-\eta \rho F) /(1-\eta) \Delta$ there is no one using an intermediary.

The bureaucrat's profits are

$$
\Pi^{b}=\eta \Delta \frac{\left(1-G\left(\theta_{d}\right)\right)^{2}}{g\left(\theta_{d}\right)}+(1-\eta) \Delta \frac{\left(1-G\left(\theta_{i}^{b}\right)\right)^{2}}{g\left(\theta_{i}^{b}\right)},
$$

where $\theta_{d} \in[\underline{\theta}, \bar{\theta})$ and $\theta_{i}^{b} \in\left(\theta_{d}, \bar{\theta}\right)$.

Lemma 5 (Existence). When $b_{d} \neq \emptyset$ and $b_{i} \neq \emptyset i$ t must be that $\rho F \leq c \leq(1-\eta) \Delta \bar{\theta}+\eta \rho F$. 
This lemma is established in the discussion above. For clarity we summarize the results of this section in a table.

\begin{tabular}{lllll}
\hline & \multicolumn{2}{l}{ Case } & \\
\cline { 2 - 4 } & No bribes & Only directly & Only by intermediaries & Both directly and by intermediaries \\
\hline Critical type(s) & - & $H\left(\theta_{d}\right)=\frac{\rho F}{\Delta}$ & $H\left(\theta_{i}\right)=\max \left\{\frac{c}{\Delta}, 0\right\}$ & $H\left(\theta_{d}\right)=\frac{\rho F}{\Delta}, \quad H\left(\theta_{i}^{b}\right)=\frac{c-\eta \rho F}{(1-\eta) \Delta}$ \\
Bureaucrat's profits & 0 & $\eta \Delta \frac{\left(1-G\left(\theta_{d}\right)\right)^{2}}{g\left(\theta_{d}\right)}$ & $\Delta \frac{\left(1-G\left(\theta_{i}\right)\right)^{2}}{g\left(\theta_{i}\right)}$ & $\eta \frac{\left(1-G\left(\theta_{d}\right)\right)^{2}}{g\left(\theta_{d}\right)}+(1-\eta) \Delta \frac{\left(1-G\left(\theta_{i}^{b}\right)\right)^{2}}{g\left(\theta_{i}^{b}\right)}$ \\
Bribe fees $\left(\left\{b_{d}, b_{i}\right\}\right)$ & $\{\emptyset, \emptyset\}$ & $\left\{\eta \theta_{d} \Delta, \emptyset\right\}$ & $\left\{\emptyset, \theta_{i} \Delta-c\right\}$ & $\left\{\eta \theta_{d} \Delta, \eta \Delta \theta_{d}+(1-\eta) \Delta \theta_{i}^{b}-c\right\}$ \\
Existence condition & - & $\bar{\theta} \Delta>\rho F$ & $\bar{\theta} \Delta>c$ & $(1-\eta) \Delta \bar{\theta}+\eta \rho F \geq c \geq \rho F$ \\
\hline
\end{tabular}

\subsection{The equilibrium}

In the previous subsection we analyzed the four options available to the bureaucrat. Since he has first mover's advantage we now find the equilibrium by finding out which option maximizes his profits. Notice that by revealed preferences one should expect that if bureaucrats can take bribes both directly and indirectly, then this will be profit maximizing. In general the only reason to constrain your choices is if one of your unconstrained choices is not feasible, and that is what occurs here. We actually prove that if taking bribes both directly and through intermediaries is feasible, it has a strictly higher profit. If this does not happen then the bureaucrat falls back on choosing the cost minimizing option. The cost of decreasing regulations when one takes a bribe from an intermediary is $c$, the implicit cost of reducing regulations when one takes a bribe from the client is $\rho F$, and if $c \leq \rho F$ the bureaucrat only accepts bribes from intermediaries. The bureaucrat only takes bribes directly when both of the above conditions fail, or $c \geq(1-\eta) \Delta \bar{\theta}+\eta \rho F$. This is the essence of Proposition 1 in Section 4.2.1; in Section 4.2.2 we discuss the possible equilibria under optimal government policy.

\subsubsection{Equilibrium with all government policies}

\section{Proposition 1. In equilibrium if}

1. $\rho F<c / \eta-((1-\eta) / \eta) \Delta \bar{\theta}$, then all bribers directly bribe the bureaucrat;

2. $c / \eta-((1-\eta) / \eta) \Delta \bar{\theta} \leq \rho F<c$, then some bribers use intermediaries and some directly bribe the bureaucrat;

3. $\rho F \geq c$, then all bribers use intermediaries.

Notice how much more common corruption is due to intermediaries. The conditions of Lemma 1 offer a wide variety of policies that could stop corruption; in Proposition 1 it is impossible to stop bribery. This greatly limits government's ability to control corruption.

As an example of this equilibrium consider the simple case where $G(\cdot)$ is the uniform distribution with an upper bound of $\bar{\theta}$ and a lower bound of $\underline{\theta}$. Then $\theta_{d}=(1 / 2)((\rho F+\bar{\theta} \Delta) / \Delta), \theta_{i}^{b}=(1 / 2)((c-\eta \rho F-(1-\eta) \Delta \bar{\theta}) /(1-\eta) \Delta)$, and $\theta_{i}=(1 / 2)((c+\bar{\theta} \Delta) / \Delta)$, and the profit under each option is

$$
\begin{aligned}
\Pi^{d} & =\frac{\Delta}{4(\bar{\theta}-\underline{\theta})} \eta\left(\bar{\theta}-\frac{\rho F}{\Delta}\right)^{2}, \quad \Pi^{i}=\frac{\Delta}{4(\bar{\theta}-\underline{\theta})}\left(\bar{\theta}-\frac{c}{\Delta}\right)^{2}, \\
\Pi^{b} & =\frac{\Delta}{4(\bar{\theta}-\underline{\theta})}\left(\eta\left(\bar{\theta}-\frac{\rho F}{\Delta}\right)^{2}+(1-\eta)\left(\bar{\theta}-\frac{c-\eta \rho F}{(1-\eta) \Delta}\right)^{2}\right) ;
\end{aligned}
$$

it is easy to see that when both are possible $\Pi^{b}>\Pi^{d}$, and with a little more algebra one can show that $\Pi^{b}>\Pi^{i}$ when $c \in(\rho F,(1-\eta) \Delta \bar{\theta}+\eta \rho F]$.

It is worth noting how our results would change if intermediaries did have some market power. We assert that if a bureaucrat uses competitive intermediaries, he still would use intermediaries if intermediaries had market power. Let us compare the profits when the bureaucrat accepts bribes from both to those when he only accepts bribes directly. The 
only difference is the extra fee the bureaucrat gets from clients who use intermediaries. If the intermediary has market power, then she would try to absorb some of these extra fees. As a result $\theta_{i}$ and $\theta_{i}^{b}$ would both increase. However, if the intermediary raises her fees too high, then no one will use intermediaries, and she will be out of business. Thus, the intermediary would still make it profitable for the bureaucrat to employ her services. A secondary effect is that the bureaucrat would be reluctant to take bribes only from intermediaries. If a bureaucrat takes bribes only from intermediaries he is giving intermediaries market power over a complimentary good, and as Shleifer and Vishny (1993) illustrate, this gives rise to a double markup and lowers profits for the bureaucrat. Taking bribes directly from clients provides competition for the intermediary, and bureaucrats would take bribes from both more frequently.

\subsubsection{Equilibrium with optimal expected punishment}

In this section, we will find optimal expected punishment by government and show that under optimal expected punishment, if all bribery takes place via intermediaries, then the opportunity cost of using an intermediary must be negative.

To find optimal expected punishment, we define the external cost of policy variables function $e C\left(\rho, F, \eta, \Delta \mid Q_{b}(d)\right)$, where $Q_{b}(d)$ is the number of bribers who bribe the public official directly. The impact of $Q_{b}(d)$ is due to the positive cost of enforcing a fine, the court costs or costs of imprisonment. Using the welfare function in Polinsky and Shavell (2000), we can derive a more explicit functional form for this cost function ${ }^{3}$ :

$$
e C\left(\rho, F, \eta, \Delta \mid Q_{b}(d)\right)=\eta \rho\left(\psi_{1}(F)-F\right) Q_{b}(d)+\psi_{2}(\rho, F, \eta, \Delta) .
$$

If we assumed that $\psi_{1}(F)=0$ then we could ignore the first term since it would be a transfer between the bureaucrat and public. However, this assumption would be unreasonable even in the case where $F$ is a simple monitory fine. There is always a costly appeal process before fines are applied. The function $\psi_{2}$ represents the capacity costs of being able to impose fines or prison sentences $(F)$, monitoring costs $(\rho)$, and the costs of decreasing either the reliability of bureaucrats $(\eta)$ or the amount they can reduce regulations $(\Delta)$.

Unlike a traditional cost function there is no reason to assume that the marginal cost of any of these parameters is positive or negative. In fact it is not uncommon that analysts assume $\partial e C / \partial F<0$, or that the money collected from the bureaucrat can be put to good use. What we will assume is as follows.

Assumption 2. Increasing the level of monitoring $(\rho)$ has a positive marginal external cost, or $\partial e C / \partial \rho>0$.

If this is true then simple optimization shows that at any optimal level of regulation $\partial e C / \partial F>0$.

Lemma 6. At any optimal level of expected punishment, $z=\rho^{*} F^{*}$ then either $\partial e C / \partial F>0$ or $z=0$.

This insight was first derived by Becker (1968), who assumes that there is a finite upper bound on $F$ and shows optimally $F$ will equal this limit. As in that paper the intuition behind this result is immediate; if society benefits from increasing $F$ and decreasing $\rho$ then it is obvious what to do. It is only when both techniques are costly that society might want to limit $F$. Increasing fines may result in higher litigation related costs and hence higher costs for the society. The higher the penalty of being caught for corruption, the greater the incentive of the bureaucrat to avoid paying that

${ }^{3}$ Explicitly rewriting their welfare function using our notation we get
\[ \int_{\theta_{i}}^{\bar{\theta}} \Delta g(\theta) \mathrm{d} \theta+\int_{\theta_{d}}^{\theta_{i}} \eta \Delta g(\theta) \mathrm{d} \theta-\eta \rho F Q_{b}(d)-\left(1-G\left(\theta_{i}\right)\right) h-Q_{b}(d) \eta h-\left(-Q_{b}(d) \eta \rho F+e\right), \]

where $h$ is the harm imposed on society from corruption and $\rho$ is an increasing function of $e$. Note that if no one uses intermediaries $\theta_{i}=\bar{\theta}$, and if no one bribes directly then $\theta_{i}=\theta_{d}, Q_{b}(d)=0$.

In this function the first three terms is the direct impact of the policy on the clients and bureaucrats, and the next two represent the direct harm to society of the corruption. Thus the external cost of policy variables is the last two terms, or

$$
e C\left(\rho, F, \eta, \Delta \mid Q_{b}(d)\right)=-Q_{b}(d) \eta \rho F+e .
$$

Since we have multiple policy variables we find it convenient to write $e=\psi_{2}(\rho, F, \eta, \Delta)$, and we depart from Polinsky and Shavell's analysis by arguing that there is a positive cost to imposing fines of $\psi_{1}(F) Q_{b}(d)$, leaving us with our final cost function. 
penalty. In such an environment, prosecution will be more costly. We refer the reader to Polinsky and Shavell for a complete discussion of this issue.

Corollary 1. If and only if all clients are using intermediaries can the opportunity cost of using the intermediary be negative under optimal government policy.

This is a simple and testable implication of our model. In any market where everyone uses intermediaries it must be that the regulation requires so much knowledge and expertise that only an intermediary can handle it efficiently. However, notice that this does not prove that there is corruption. The negative opportunity cost of the intermediary does not depend on her ability to reduce the level of regulation. In such a market everyone uses intermediaries even if there is no corruption.

\section{Fighting corruption}

Since our paper necessarily only has a partial model of the economy, if we were to construct a welfare function, both the benefits of regulation and the cost of policy variables would necessarily be a reduced form function. This would complicate analysis without increasing our understanding of the fundamentals; thus instead we focus on a simpler objective where the impact of policy variables is clear within our analysis: the impact of intermediaries and policy variables on the quantity of regulation $\left(Q_{r}\right)$. An analyst or government with a well-specified general welfare function can then take our analysis of this variable as an input into their welfare maximization.

The implicit assumption is that it is welfare maximizing to have all clients face the given optimal regulation level. This is appropriate if not meeting the regulation imposes some externality on the economy. Hence, when we say a policy will increase regulation we mean that the increase is towards the optimal quantity. Regulation can also address allocational issues (see Guriev, 2004 for example) but in our paper we are not considering this type of regulation.

We will consider three policy variables, $\eta, \rho F$, and $\Delta$. The first one $(\eta)$ represents the trustworthiness of bureaucrats; $\eta$ near one means the bureaucrat is trustworthy. If a client tries to bribe him directly then he almost always reduces the regulation. This can be reduced by moving bureaucrats around in the government; if a bureaucrat is not in one department for long he cannot develop a reputation for taking bribes, and thus it is not worth it to him to reduce regulation level. Bardhan suggests periodic job rotation as an anti-corruption measure, so that a bureaucrat does not become too cozy with a customer over a long period. We assume that it is not possible to reduce $\eta$ to zero.

The second variable $(\rho F)$ is the expected punishment; as discussed above in our model it does not affect anything to vary the probability of an investigation $(\rho)$ and the fine imposed $(F)$ independently, thus we will simplify the discussion by only changing them jointly. The third variable $(\Delta)$ represents the amount of control the bureaucrat has over the level of regulation. Government can control this variable to a limited degree by making the bureaucrat provide more documentation and signatures from other bureaucrats. In the absence of intermediary agents, limiting discretionary power of bureaucrats is considered an important tool to combat corruption (Rose-Ackerman, 1994; Bardhan, 1997; CIPE, 2003). Assume that $\Delta$ can be between $\underline{\Delta}$ and $r^{*}$, where $\underline{\Delta}>0$. We will continue to assume that the highest type can afford to use an intermediary, or that $\bar{\theta} \underline{\Delta}>c$.

Proposition 2. Intermediaries always strictly reduce the quantity of regulation by:

1. $\Delta(1-\eta)\left(1-G\left(\theta_{i}^{b}\right)\right)$ if $\rho F<c$,

2. $\Delta(1-\eta)\left(1-G\left(\theta_{i}\right)\right)+\eta \Delta\left(G\left(\theta_{i}\right)-G\left(\theta_{d}\right)\right)$ if $\rho F \geq c$ (note that $\left.G\left(\theta_{i}\right)-G\left(\theta_{d}\right)>0\right)$.

The intuition behind the quantity $\Delta(1-\eta)\left(1-G\left(\theta_{i}^{b}\right)\right)$ is immediate. The only change when intermediaries are present is for those who use them, and they have their regulation decreased by the quantity $\Delta$ with an additional probability of $1-\eta$. When $\rho F \geq c$ there is also the fact that more people now choose to offer bribes because it is "cheaper" for the bureaucrat to accept them. Notice that if intermediaries had market power, then both of these effects would be reduced. 
While this is an interesting (and not unexpected) conclusion what is more important for a government in such a situation is how well it can control the quantity of regulation. Here again the news is generally bad. Two of their three instruments have a reduced level of power, and what formerly increased regulation will sometimes decrease it. For simplicity we will assume in the following proposition that $\left\{\theta_{d}, \theta_{i}, \theta_{i}^{b}\right\}$ are all in the interior of the support of $\theta-[\underline{\theta}, \bar{\theta}]$. The reader can clearly extend the analysis to the cases where this is not true.

Proposition 3. Assume that $c>0$. Then when there are no intermediaries increasing expected punishment $(\rho F)$ and decreasing the reliability of bureaucrats $(\eta)$ and the amount they can change regulation $(\Delta)$, increase the quantity of regulation.

When intermediaries are present increasing expected punishment and reducing bureaucrat's trustworthiness are less effective in increasing the level of regulation. In fact these policies may decrease the quantity of regulation.

On the other hand decreasing the amount of control that the bureaucrat has over the level of regulation $(\Delta)$ is more effective than before.

The intuition behind the negative results on the effects of increasing $(\rho F)$ and decreasing $(\eta)$ is that while they decrease the number of clients who successfully offer bribes directly, they also increase the number of clients who switch to using intermediaries. This always reduces the impact of control variables, and if the switching effect outweighs the direct effect, then this can result in less regulation.

One can explicitly derive that

$$
\frac{\partial Q_{r}^{b}}{\partial \rho F}=\eta\left(\frac{g\left(\theta_{d}\right)}{H^{\prime}\left(\theta_{d}\right)}-\frac{g\left(\theta_{i}^{b}\right)}{H^{\prime}\left(\theta_{i}^{b}\right)}\right), \quad \frac{\partial Q_{r}^{b}}{\partial \eta}=(c-\rho F)\left(\frac{1}{(1-\eta)} \frac{g\left(\theta_{i}^{b}\right)}{H^{\prime}\left(\theta_{i}^{b}\right)}-\frac{\Delta}{c-\rho F}\left(G\left(\theta_{i}^{b}\right)-G\left(\theta_{d}\right)\right)\right) .
$$

Notice that $\partial Q_{r}^{b} / \partial \rho F$ is nothing more than the sum of the direct effect and the switching effect. The direct effect is $g\left(\theta_{d}\right) / H^{\prime}\left(\theta_{d}\right)>0$ and the switching effect is $-g\left(\theta_{i}^{b}\right) / H^{\prime}\left(\theta_{i}^{b}\right)<0$; if the latter dominates the former then this derivative has the wrong sign. The equation for $\partial Q_{r}^{b} / \partial \eta$ is more complicated because $\eta$ has a level effect (the second term) and a derivative effect (the first term). The direct effect is a pure level effect: $-\Delta /(c-\rho F)\left(1-G\left(\theta_{d}\right)\right)<0$. The switching effect is both a level and derivative effect:

$$
\frac{\Delta}{c-\rho F}\left(1-G\left(\theta_{i}^{b}\right)\right)+\frac{1}{(1-\eta)} \frac{g\left(\theta_{i}^{b}\right)}{H^{\prime}\left(\theta_{i}^{b}\right)}>0 .
$$

For an arbitrary distribution it is hard to know when these equations will have the wrong sign, but one can easily check that with the uniform distribution $Q_{r}^{d}=r^{*}-\eta(1 / 2)((\bar{\theta} \Delta-\rho F) /(\bar{\theta}-\underline{\theta}))$ and $Q_{r}^{b}=Q_{r}^{i}=r^{*}-(1 / 2)((\bar{\theta} \Delta-c) /(\bar{\theta}-$ $\underline{\theta})$ ), or once some clients use intermediaries, $\eta$ and $\rho F$ are ineffective.

If intermediaries had market power then we cannot be sure what would happen to the switching effect. While the number of clients using intermediaries will be lower if intermediaries have market power, this imposes little constraint on the derivatives. If the intermediaries' derived demand curve is elastic, they might decide to reduce their fee significantly when the exogenous variable changes, and this would exacerbate the switching effect. On the other hand if it is inelastic they might increase their fee, thus counteracting and possibly reversing the switching effect.

We would like to qualify the most positive statement in this proposition, that reducing $\Delta$ can increase the quantity of regulation. This is generally done by requiring several bureaucrats to sign off on each regulation or imposing other internal checks of each bureaucrat's actions. However, one should notice that this increases the complexity of regulation, thereby increasing the benefit of using someone who knows the regulation such as an intermediary. Mathematically this implies $\partial c / \partial \Delta>0$, and we assert that complexity of regulation is the only reason that $c$ might be less than zero. In a preliminary version of this paper we showed that these considerations can outweigh the direct benefits of reducing $\Delta$ because if the impact on $c$ is large enough, then the benefit of reducing $\Delta$ is outweighed by the cost of decreasing $c$.

\section{Discussion and conclusion}

In this paper we analyzed the effects of intermediary agents on corruption and regulation and discussed whether solutions to the corruption problem change in the presence of intermediaries. In our analysis the level of regulation set by the government is assumed to be optimal. Clients may pay bribes directly or indirectly (using intermediaries) to circumvent the necessary regulations. 
We show that if intermediaries are economically viable, then they always reduce the quantity of regulation below its optimal level. Furthermore, policies such as increasing expected punishment for the corrupt bureaucrat and moving bureaucrats around to prevent entrenchment are less effective in increasing the level of regulation towards the efficient level. In fact these policies may decrease the quantity of regulation. Limiting the discretionary power of the bureaucrat is the only policy that might be more effective in the presence of intermediaries. However, even this needs to be exercised with caution. In order to limit the discretionary power of bureaucrats governments often rely on excessive documentation and multiple signatures which would in turn increase the benefit of using intermediaries.

The primary implication of our work is that ignoring intermediaries will lead to misguided policies, which might make corruption worse. This point is also supported by case studies like Fjeldstad (2003). The Tanzanian government launched an anti-corruption campaign by firing all corrupt bureaucrats. Private businesses immediately hired these bureaucrats, who used their insider contacts to construct new corruption networks. What seemed like a simple solution increased the problem because the government ignored the market for intermediaries.

What are the possible solutions then to the corruption problem in the presence of intermediaries? Increasing opportunity cost of using an intermediary by simplifying red tape and not moving bureaucrats around may help reduce corruption. Regulation of intermediaries should help as well; if intermediaries could not advertise or work for large corporations without a license, then it would be possible to monitor their behavior and audit their accounts. It would also be helpful to hold clients accountable if intermediary agents pay bribes on their behalf. What is clear is that if governments ignore the problem of intermediaries, then they will have little success in eliminating corruption.

\section{Acknowledgements}

We would like to thank the editor, the two anonymous referees, Lambros Pehlivanos, participants at the 2003 Econometric Society Summer Meetings and seminar participants at the Athens University of Economics and Business for their helpful comments.

\section{Appendix A. Supplementary data}

Supplementary data associated with this article can be found, in the online version, at doi:10.1016/j.jebo.2006.06.015.

\section{References}

Bardhan, P., 1997. Corruption and development: a review of issues. Journal of Economic Literature 35, 1320-1346.

Bayar, G., 2005. The role of intermediaries in corruption. Public Choice 122, $277-298$.

Becker, G.S., 1968. Crime and punishment: an economic approach. Journal of Political Economy 76, 169-217.

Bowles, R., Garoupa, N., 1997. Casual police corruption and the economics of crime. International Review of Law and Economics 17, 75-87.

Campos, J., Lien, D., Pradhan, S., 1999. The impact of corruption on investment: predictability matters. World Development 27, $1059-1067$.

Center for International Private Enterprise (CIPE), November 2003. Evaluation of anti-corruption programs. http://www.cipe.org/programs/ evaluations/Anti_Corruption_Report_2003.pdf.

Control Risks Group, Information Services Team, 1998. Corruption and Integrity: Best Business Practice in an Imperfect World. Control Risks Group Ltd., London.

della Porta, D., Vanucci, A., 1999. Corrupt Exchanges, Actors, Resources and Mechanisms of Political Corruption. de Gruyter, New York.

Fjeldstad, O., 2003. Fighting fiscal corruption: lessons from the Tanzania revenue authority. Public Administration and Development 23, 165-175.

Garoupa, N., Klerman, D., 2004. Corruption and the optimal use of nonmonetary sanctions. International Review of Law and Economics 24 , 219-225.

Guriev, S., 2004. Red tape and corruption. Journal of Development Economics 73, 489-504.

Kaufmann, D., Wei, S.J., 2000. Does grease money speed up the wheels of commerce? IMF Working Paper No. 00/64. Available at SSRN: http://ssrn.com/abstract=879552.

Lambsdorff, J.G., 2002a. Confidence and illegal transactions. American Journal of Economics and Sociology 61, 829-853.

Lambsdorff, J.G., 2002b. Making corrupt deals: contracting in the shadow of the law. Journal of Economic Behavior and Organization 48, $221-241$. Oldenburg, P., 1987. Middlemen in third world corruption. World Politics 39, 508-535.

Polinsky, A.M., Shavell, S., 2000. The economic theory of public enforcement of law. Journal of Economic Literature 38, 45-76. 
Polinsky, A.M., Shavell, S., 2001. Corruption and optimal law enforcement. Journal of Public Economics 81, 1-24.

Rose-Ackerman, S., 1994. Reducing bribery in the public sector. In: Trang Duc, V. (Ed.), Corruption and Democracy: Political Institutions, Processes and Corruption in Transition States in East-Central Europe and in the Former Soviet Union. Institute for Constitutional and Legislative Policy, Budapest, pp. 21-28.

Shleifer, A., Vishny, R., 1993. Corruption. Quarterly Journal of Economics 108, 599-617.

Wiehen, M., 1999. The Integrity Pact (TI-IP): The Concept, the Model and the Present Applications. A Status Report as of November 1, 1999. Transparency International, Berlin. 